\title{
DESEM, Dokuz Eylül University lifelong learning center: Community-based, multilayer training support on lifelong
}

\author{
Ahu Pakdemirli ${ }^{1,3 a}$, Yasemin Baskın ${ }^{2,3}$, Serdar Nart $^{3,4}$, Lale Gert ${ }^{3}$, Deniz Kuru ${ }^{3}$, Hülya \\ Ellidokuz ${ }^{2,3}$ \\ ${ }^{1}$ Vocational Higher School of Healthcare Studies, Dokuz Eylul University, Izmir, Turkey \\ ${ }^{2}$ Institute of Oncology, Dokuz Eylul University, Izmir, Turkey \\ ${ }^{3}$ Continuing Education Center, Dokuz Eylul University (DESEM), Izmir, Turkey \\ ${ }^{4}$ Faculty of Law, Dokuz Eylul University, Izmir, Turkey
}

\begin{abstract}
Dokuz Eylul University Continuing Education Center has become a place, focusing on current and universal information transfer, bringing together the university students and also who live in Izmir and residential areas. Personal development is the lifelong process of understanding self-individual, developing and assessing the skills and qualities, considering their aims in life in order to achieve maximum potential. The course modules have been designed to provide in-depth training in the supporting of the academic progress, personal development, and long life learning on arts, literature and history. Personal development should be an important part of Lifelong Learning with multilayer training support.
\end{abstract}

\section{Introduction}

DESEM, Dokuz Eylul University Lifelong Learning Center, has become a place, focusing on current and universal information transfer, of meeting and bringing together for those not only who are the university students but also who live in Izmir and residential areas around it from every walk of life by the courtesy of the works of itself together with its academic personnel. For this respect, it maintains its existence with successful results in reaching more and more people.

Learning to know, to do, to be and to live together are basic educational achievements ,[3]. This involves learning new skills and also adapting old ones, being able to overcome problems, capable of easy communicate with others, identifying needs to be learned effectively, [5].

\footnotetext{
${ }^{a}$ Corresponding author: ahu.pakdemirli@deu.edu.tr
} 


\section{Lifelong Learning}

Lifelong learning term is widely used in a variety of contexts such as home schooling, continuing education, knowledge work, personal learning environments, and adult education. Continuing education is usually offered by universities or higher education institutions as a postgraduate training. Lifelong Learning aims to reach knowledge for personal or professional reasons as self-motivated and willingness and provide educational opportunities outside standard educational systems. Lifelong learning increases socialization, personal development and self-sustainability.

Lifelong learning is described as learning throughout life where the learning is flexible, diverse and available at different times/place and also crosses sectors, promoting learning beyond traditional schooling and throughout adult life, [4]. Jacques Delors reported 'Learning: The Treasure Within', referred as the 'Delors Report', integrated vision of education based on the paradigms of lifelong learning, and the four pillars of learning to be, to know, to do, and to live together ,[3]. According to this 'learning to know' is for learning to learn and to benefit from the opportunities education provides throughout life, while 'learning to do' is for equipping people for different types of work required and learning to deal with many situations and work in teams. 'Learning to live together' brings peaceful solutions and makes an understanding of different cultures. 'Learning to be' gives a total look to person's education including mind and body, intelligence, sensitivity, and spirituality.

There have been many descriptions for Lifelong Learning [1], [9], [11]. The European Lifelong Learning Commission defines lifelong learning as "All learning activity undertaken throughout life, with the aim of improving knowledge, skills and competences within a personal, civic, social and/or employment-related perspective", [6].

According to all these definitions, Lifelong Learning can be thought as combination of processing person's body and mind throughout life time.

\section{Personal Development}

Personal development is the lifelong process of understanding self-individual, developing and assessing the skills and qualities, considering their aims in life in order to achieve maximum potential. Personal development programs includes activities that improve awareness and identity, develop talents and potential, create human source and facilitate employability, enhance quality of life and contribute to the realization of yearnings and dreams.

Personal development includes improving self-awareness and self-knowledge, learning or improving new skills, developing talents, improving wealth, identifying potential, building employability, becoming a self-leader, renewing self-esteem, spiritual development, enhancing lifestyle and improving the quality of life, initiating personal autonomy and providing social abilities.

Personal development is not just for one individual, it also helps developing other people. This can be in different roles such as those of a teacher or mentor, either through a personal competency and a professional service like providing training, assessment or coaching.

Adult education requires active participation in of the individuals in society, throughout their lives. For this reason the content of most programs for adults includes continuous vocational and professional training, achieving professional reorientation or adapting to activities using new technologies and calls for technical elements and creativity that have not been provided to the adult through initial training. Universities also focus on other specific areas of adult education, such as personal development, [10]. 
People's moral and ethical standards are dictated by universal laws and cultural influences and personal development programmes can increase feelings of guilt and reduce feelings of shame, [7].

\section{DESEM}

Dokuz Eylul University Lifelong Learning Center, DESEM, is living by creating today and tomorrow, "human subject to - the legal basis, institutional independent as a basis for ethical rules and principles, developers, critics, changer, conciliatory, awareness creative, thoughtful, collaborative, facilitative, authority sword and the validity of the available requirements - knowledge; adequate, competent and skilled practitioners to provide based on the contributions of scientists, sustainability and continuity of abandoning. DESEM, which was founded to transfer all information and experience which was produced in various departments in our University to all walks of life, together with a lot of participants from students to housewives, from businessmen to state officers has met in activities organized, they have had the opportunities to watch all new developments in art, culture and science world with the service quality that the University presents. In this regard, it has 75th Year Lecture Hall: for 385 people, Claret Red Hall: for 238 people, Blue Hall: for 98 people, Computer lab: for 45 people, 6 classes for 20 people each. So, total 871 people are able to use them at the same time.

DESEM has become a place, focusing on current and universal information transfer, of meeting and bringing together for those not only who are the university students but also who live in Izmir and residential areas around it from every walk of life by the courtesy of the works of itself together with its academic personnel. For this respect, it maintains its existence with successful results in reaching more and more people.

When personal development takes place in the context of DESEM, it refers to the methods, programs, tools, techniques, and assessment systems that promote human development at the individual level in DESEM.

The course modules have been designed to provide in-depth training in the supporting of the academic progress, personal development, and long life learning on arts, literature and history listed below.

Foreign language and language skill courses (translation, proficiency and advance levels) for English, German French, Spanish, Russian, Japanese, Ottoman. Speed Reading Course, Course for Public Servants Exam and Foreign Language Exam. Applied Statistics Analysis Course in Health, Coaching and Mentoring Training of Trainers Certification Program, Negotiation and Mediation School, Scientific Research and Training Program in Health Sciences, Mind Games Teaching and Intelligence Certificate Program, Strategic Human Resources Management, Coaching and Mentoring Training of Trainers Certification Program, Medicine and Health Law Basic Education Certificate Program, Teaching Staff Training program, Archaeology and Art History Course, photography Workshop, Cinematheque, Culture and Science; Poetry, Philosophy and Psychoanalysis; Sufi and Literature; Novels, philosophy and psychoanalysis; Imaginative topographies on Literature and Cinema; The modern history of Political Thought, [12].

\section{Conclusion}

Personal development should be an important part of Lifelong Learning with multilayer training support. Adult education has two major components as professional and personal development where universities play big role on this. Not just for professional life, universities must provide support for the social life as well. Long-term goals should shape 
the social changes and also should support adults to upgrade to a better level of business education.

The adult training programs should consider adult expectations such as specific modality of training or education for better results. Adult educators also regard the fact that these adults have some training and a life experience which may be useful in the development of ongoing educations and programs, [8].

The results depends on the adult training experiences through which adults' actual personal need of continuously educating themselves. The main role of adult training courses is to focus on the principles of stimulating, motivating, relevant and effective teaching with a concrete impact in professional and personal life, [2].

Formal learning, personal learning orientation and impact of informal learning on a supportive learning environment. Some of these courses because they cannot be associated with formal education or training system cannot even be described as learning activities, nevertheless related to continuous changes to adapt to adult roles, it must be regarded as forming activities in all aspects of life.

In this context, universities should support social and working life, cover innovative, flexible, and new technologies, deliver accessible and sustainable educational opportunities to society. Continuing education centers have important position in this field and they can form a bridge between the university and the community.

\section{References}

1. Billett, S., Lifelong learning and self: work, subjectivity and learning. Studies in Continuing Education, 32 (1), pp. 1-16, (2010).

2. Choi, W.,\& Jacobs, R.L., Influences of formal learning, personal learning orientation, and supportive learning environment on informal learning. Human Resource Development Quarterly, (2011).

3. Delors, J., Learning: The treasure within Report to UNESCO of the International Commission on Education for the Twenty-first Century, UNESCO, (1996).

4. Duţă, N., \& Rafailă E., Importance of the lifelong learning for professional development of university teachers - needs and practical implications.Procedia - Social and Behavioral Sciences 127 ( 2014 ) 801 - 806, (2014).

5. Enache, R., \& Crişan, A., Communication, Networking and Personal Development Skills Trained During the Educational Process. Procedia - Social and Behavioral Sciences 159 ( 2014 ) 524-528, (2014).

6. European Commission (EC)., Making a European area of lifelong learning a reality. Brussels: European Commission, (2001).

7. Golu, F., \& Gorbunescu, A., Applications of personal development in the re-education of imprisoned women. Procedia - Social and Behavioral Sciences 127 ( 2014 ) 606 610, (2014).

8. Kappe, R., Smits, R., \& Bekker, E., Training-model for assessors of Inholland University. Amstelveen, Inholland/ECI, (2011).

9. Naimpally, A., Ramachandran, H., Smith, C., Lifelong Learning for Engineers and Scientists in the Information Age. USA: Elsevier. pp. 1 10, (2012).

10. Stana, C., The role of universities in promoting personal development of the participants, through education programs for adults. Procedia - Social and Behavioral Sciences 142, $207-213$, (2014).

11. Watson, L., Lifelong Learning in Australia, Canberra, Department of Education, Science and Training, (2003).

12. http://desem.deu.edu.tr/index.php?lang=en (date accessed: 2015). 